This is the peer reviewed version of the following article: L. Meabe, N. Goujon, C. Li, M. Armand, M. Forsyth, D. Mecerreyes, Batteries \& Supercaps 2020, 3, 68, which has been published in final form at https:// doi.org/10.1002/batt.201900119. This article may be used for non-commercial purposes in accordance with Wiley Terms and Conditions for Use of Self-Archived Versions.

\title{
Single-ion conducting poly(ethylene oxide carbonate) as solid polymer electrolyte for lithium batteries
}

\author{
Leire Meabe, ${ }^{[a]}$ Nicolas Goujon, ${ }^{[b]}$ Chunmei Li, ${ }^{[c]}$ Michel Armand, ${ }^{[c]}$ Maria Forsyth, ${ }^{[b, d]}$ David Mecerreyes ${ }^{*}$ \\ $[\mathrm{a}, \mathrm{d}]$
}

\begin{abstract}
Single-ion conducting polymer electrolytes (SIPE) have attracted a lot of interest for application in high energy density lithium metal batteries. SIPEs possess lithium transport numbers close to unity, which does not provoke concentration gradients and holds the promise of limiting lithium dendrite formation. In this article, we have optimized a single-ion polymer incorporating the most successful chemical units in polymer electrolytes, such as ethylene oxide, carbonate and a lithium sulfonimide. This single-ion poly(ethylene oxide carbonate) copolymer was synthesized by polycondensation between polyethylene glycol, dimethyl carbonate and a functional diol including the pendant sulfonamide anionic group and the lithium counter-cation. By playing with the monomer stoichiometry, the crystallinity and ionic conductivity were optimized. The best copolymer showed high ionic conductivity values of $1.2 \cdot 10^{-4} \mathrm{~S} . \mathrm{cm}^{-1}$ at $70^{\circ} \mathrm{C}$. Lithium interactions and mobility were studied by lithium pulsed field gradient, lithium diffusion, NMR relaxation time measurements and FTIR-ATR analysis. High lithium mobility is observed which is due to the weakly coordinating chemical environment in the polymer and also that the sulfonamide in the SIPE adopts to a greater extent the cis conformation, which is known to promote lithium mobility. Finally, the performance of the singe-ion conducting poly(ethylene oxide carbonate) was compared in lithium symmetric cells versus an analogous conventional salt in polymer electrolyte, showing improved performance in lithium plating and stripping.
\end{abstract}

\section{Introduction}

Poly(ethylene oxide) PEO host incorporating a lithium salt has been the gold standard solid polymer electrolyte (SPE) in the area of lithium batteries for more than 40 years. Nowadays, other polymers such as polycarbonates are being extensively investigated as alternatives to PEO due to the possibility of lithium coordination by carbonate groups and the higher lithium transference number of its SPEs $\left(\mathrm{T}_{\mathrm{Li}+}>0,5 \mathrm{vs}\right.$. $\mathrm{T}_{\mathrm{Li}+}>0,2$ for PEO) ${ }^{[1]}$ A popular approach to further improve lithium transport numbers $\left(T_{L_{i}+}>0,8\right)$ consists of anchoring the negatively charged ion to the polymeric chain, named then as single-ion conducting polymer electrolytes (SIPEs). Several monomers including weak

[a] L. Meabe, Dr. D. Mecerreyes, POLYMAT, University of the Basque Country UPV/EHU, Joxe Mari Korta Centre, Avda. Tolosa 72, 20018 Donostia-San Sebastián, Spain

E-mail: david.mecerreyes@ehu.es

[b] Dr. N. Goujon, Dr. M. Forsyth, Institute for Frontier Materials (IFM), Deakin University, Waurn Ponds VIC 3216, Australia

[c] Dr. C. Li, Dr. M. Armand, CIC Energigune, Alava Technology Park, Albert Einstein 4801510, MIÑANO Álava, Spain

[d] Dr. M. Forsyth, Dr. D. Mecerreyes, Ikerbasque, Basque Foundation for Science, E-48011 Bilbao, Spain

Supporting information for this article is given via a link at the end of the document. anionic species have been investigated ${ }^{[2]}$ the most studied SIPEs being the lithium poly(styrene sulfonyl(trifluoromethylsulfonyl)imide systems. ${ }^{[3]}$ This polymer and its methacrylic version have been included in a variety of block copolymer formulations combining it with PEO segments aiming at improving its ionic conductivity values. ${ }^{[4]}$ Nowadays, the best SIPEs reported in the literature from this combination of PEO and pending sulfonamide units demonstrate ionic conductivity values of $10^{-4} \mathrm{~S} \mathrm{~cm}^{-1}$ at $70{ }^{\circ} \mathrm{C}$ and lithium transference numbers close to unity. ${ }^{[5]}$

On the other hand, several groups have recently reported the successful combination of ethylene oxide (EO) units and carbonate groups in the same copolymer. ${ }^{[6]} \mathrm{EO}$ units tend to decrease the glass transition, and consequently, increase the ionic conductivity, whereas the favorable weak coordination of carbonates and lithium cation promotes the lithium conductivity. In line with this approach, some of us recently proposed a new class of polymer host for lithium battery applications, consisting of ethylene oxide-carbonate segment, poly(ethylene oxide carbonates). ${ }^{[6,, c]}$ We studied the ratio between carbonate and ethylene oxide units. Among all of them, specially, polycarbonate containing 34 ethylene oxide units, blended with lithium bis(fluorosulfonyl)imide salt resulted in high ionic conductivity $\left(3.2 \cdot 10^{-5} \mathrm{~S} \mathrm{~cm}^{-1}\right.$ at $25^{\circ} \mathrm{C}$ and $1.3 \cdot 10^{-3} \mathrm{~S} \mathrm{~cm}^{-1}$ at $70{ }^{\circ} \mathrm{C}$ ) and high lithium transference $(0.6)$ at $70{ }^{\circ} \mathrm{C} .^{[6 \mathrm{cc}]}$

Taking into account all these strategies, in this article we show a new single-ion conducting polymer, which incorporates all three of the most successful chemical units in the area of polymer electrolytes: ethylene oxide, carbonate ester and lithium-sulfonimide. Herein, we describe the synthesis and the characterization of single-ion conducting polycarbonates (SIPC) based on carbonate groups, soft polyethylene glycol blocks and an ester functionalized anionic diol. Polycondensation was chosen as a versatile polymerization to tailor three different polymer compositions. Free standing SIPCs were prepared by blending with a cross-linkable polyethylene glycol diacrylate, showing a decent ionic conductivity and the lithium transference number close to unity. After composition optimization of singleion conducting polymer electrolyte, the electrochemical properties and battery performance of SIPC electrolyte are compared with the analogue conventional SPE, poly(ethylene oxide carbonate).

\section{Results and Discussion}

Scheme 1 shows the synthetic route towards the single ion conducting poly(ethylene oxide carbonate) copolymers (SIPC). The polymers were synthesized by polycondensation between poly(ethylene glycol) $\left(M_{n} 1500\right)$, dimethyl carbonate and a functional diol including the sulfonimide group in a twostep melt polycondensation process. Three different copolymer 


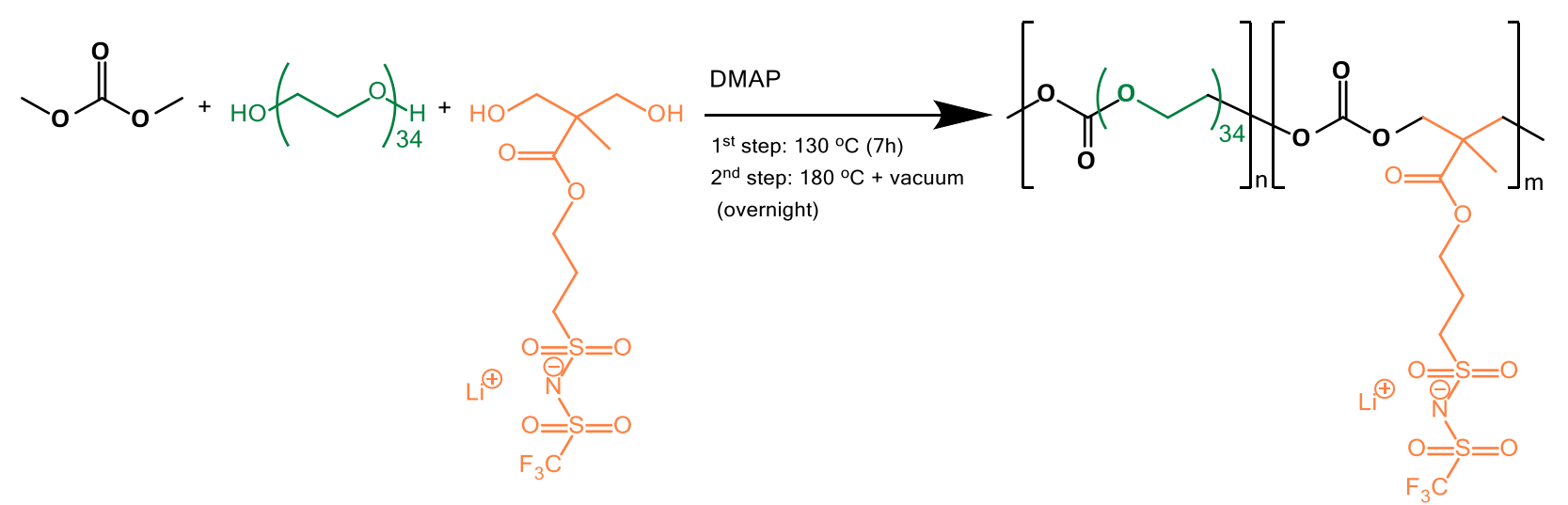

Scheme 1. Polycondensation route of poly(ethylene oxide carbonate) single-ion conducting polymer electrolytes. compositions were targeted in order to optimize the SIPE composition; $\mathrm{PEO}_{34}$ :bis-MPTFSI (lithium ((3-((3-hydroxy-2(hydroxymethyl)-2-methylpropanoyl)oxy)propyl)sulfonyl) (trifluoromethyl)sulfonyl)amide) $75: 25$ mol\% (SIPC-1), 50:50 mol\% (SIPC-2), and 25:75 mol\% (SIPC-3), ( ${ }^{1} \mathrm{H}$ NMR Figure S1). The properties of the polymer compositions are summarized in Table S1. The lithium concentration was estimated (Figure S2) and a good correlation between each composition was concluded. Thus, lithium concentration is nearly three times higher in SIPC-2 (0.58 mmol Li/g polymer) than in SIPC-1 $(0.21$ $\mathrm{mmol} \mathrm{Li/g} \mathrm{polymer).} \mathrm{A} \mathrm{similar} \mathrm{increase} \mathrm{in} \mathrm{lithium} \mathrm{concentration} \mathrm{is}$ observed when comparing SIPC-3 (1.29 mmol Li/g polymer) and SIPC-2. The molar masses of the polycarbonates were analyzed, which ranged between $15-55 \mathrm{kDa}$. The dispersities obtained are in the typical range found for polycondensation processes (1.32).

Figure 1a shows the DSC traces of the PEO-PC SIPEs. Both SIPC-1 and SIPC-2 exhibits an endothermic transition at $45{ }^{\circ} \mathrm{C}$ and $41^{\circ} \mathrm{C}$, respectively, corresponding to the melting of the crystalline oligo ethylene oxide phases. On the other hand, SIPC-3 does not exhibit any melting peak, indicating the amorphous nature of the polymer. The copolymers showed low glass transition values of $-42{ }^{\circ} \mathrm{C} / \mathrm{SIPC}-1,-38{ }^{\circ} \mathrm{C} / \mathrm{SIPC}-2$ and $36{ }^{\circ} \mathrm{C} / \mathrm{SIPC}-3$. To better understand the impact of the lithium monomer incorporation on the crystallinity of EO phase, the degrees of crystallinity of the SIPCs were characterized, Equation S1. A percentage of the crystalline EO of 43 wt.\%, 38 wt. $\%$ and 0 wt. $\%$ were calculated for SIPC-1, SIPC-2 and SIPC3 , respectively, suggesting that the incorporation of the lithium monomer in the polymer chain hinders the crystallization of the EO segment. Similar observation was reported when a discrete lithium salt is added to a similar system. ${ }^{[6 b]}$

The ionic conductivities of the three SIPCs were measured in a temperature range of $100{ }^{\circ} \mathrm{C}-25^{\circ} \mathrm{C}$, and the results are presented in Figure 1b. At room temperature, the ionic conductivity of the SIPCs is as follows: SIPC-3 > SIPC2 > SIPC1. It is well known that the ion conduction of lithium ion in PEObased polymer electrolytes is governed by the segmental motion of the ethylene oxide chains in the amorphous phase. ${ }^{[7]}$ Therefore, below the melting temperature, the ion conduction of these PEO-PC SIPEs materials is mainly dictated by the degree of crystallinity of the polymer. Increasing the lithium content from $25 \mathrm{~mol} \%$ to $50 \mathrm{~mol} \%$ (SIPC-1 to SIPC-2) only results in a slight decrease of the percentage of crystalline EO phase, from $43 \%$ to $38 \%$. This coincides with a slight increase of the ionic conductivity at $25^{\circ} \mathrm{C}$, going from $1.36 \cdot 10^{-7} \mathrm{~S} \mathrm{~cm}^{-1}$ to $2.28 \cdot 10^{-7} \mathrm{~S}$ $\mathrm{cm}^{-1}$, when the lithium content is increased from $25 \mathrm{~mol} \%$ to 50 $\mathrm{mol} \%$. In the case of SIPC-3 (75 mol\%), no crystalline EO phase is formed and a significant increase of the ionic conductivity is

(a)

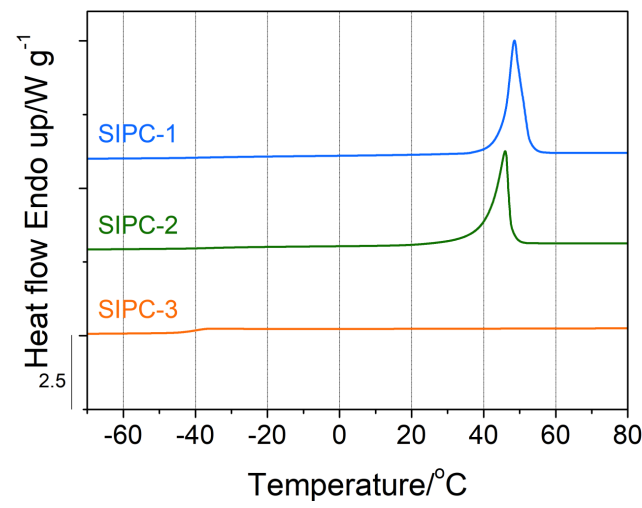

(b)

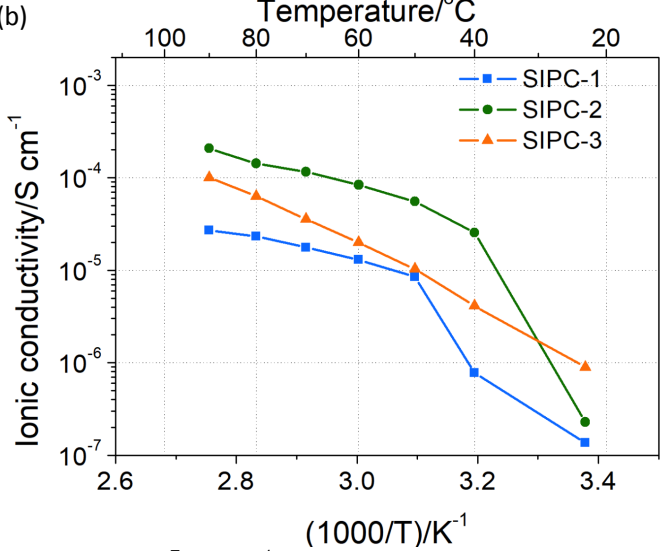

observed $\left(8.94 \cdot 10^{-7} \mathrm{~S} \mathrm{~cm}^{-1}\right.$ at $\left.25^{\circ} \mathrm{C}\right)$.

Figure 1. (a) Thermal properties of SIPC-1, SIPC-2 and SIPC-3, (DSC, $2^{\text {nd }}$ heating scan at $10 \mathrm{~K} \mathrm{~min}^{-1}$ ) and (b) ionic conductivity.

Above the melting temperature of the crystalline EO phase $\left(\mathrm{T}>50{ }^{\circ} \mathrm{C}\right.$ ), the lithium ion conduction is governed by the $\mathrm{O} / \mathrm{Li}$ molar ratio (carbonate oxygens are taken into account, Equation S2). It seems that SIPC-2 contains the best balance 
between oxygen and lithium molar ratio, $\mathrm{O}: \mathrm{Li}=35$, whereas in SIPC-1, the amount of lithium ion is too low to promote high ionic conductivity with O:Li molar $\approx 110$. On the other hand, the lower ionic conductivity of SIPC-3 $(\mathrm{O}: \mathrm{Li}=6)$ could be due to the fact that there are not sufficient carbonate/EO units available to coordinate with lithium ions and promote efficient dissociation from the anionic polymer backbone. A similar trend was observed when the same lithium based monomer salt was employed in a single ion polymer electrolyte. ${ }^{[8]}$ The SIPC-2 exhibits an ionic conductivity of $1.2 \cdot 10^{-4} \mathrm{~S}^{-\mathrm{cm}^{-1}}$ at $70^{\circ} \mathrm{C}$. It is worth mentioning that such a high value of ionic conductivity in this temperature range is unusual in a solid single-ion conducting polymer electrolyte,${ }^{[2 a]}$ and is likely due to the unique

(a)

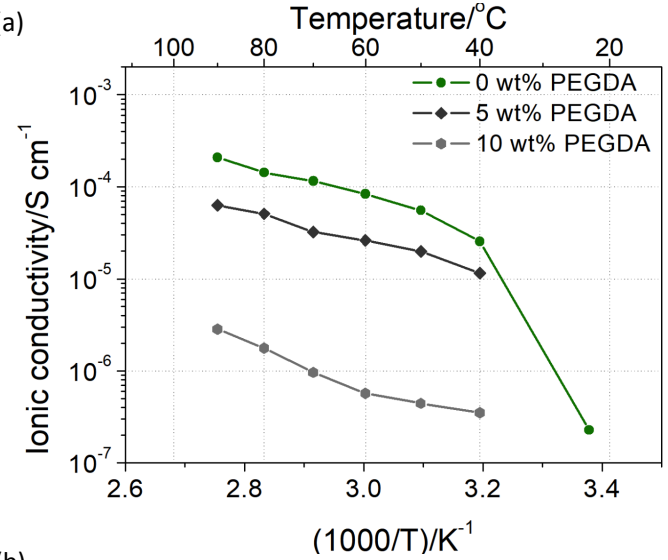

(b)

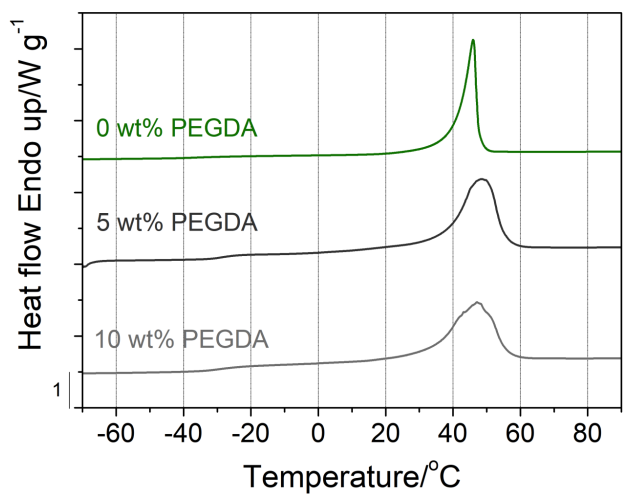

combination of ethylene oxide and carbonate units promoting ion pair dissociation. ${ }^{[9]}$

Figure 2. (a) lonic conductivity and (b) thermal properties of SIPC-2 with 0,5 and $10 \mathrm{wt} . \%$ PEGDA, (DSC, $2^{\text {nd }}$ heating scan at $10^{\circ} \mathrm{C} \mathrm{min}^{-1}$ ).

SIPCs-based polymer electrolytes have low glass transition (around $-40{ }^{\circ} \mathrm{C}$ ) and are linear polymers. Therefore, above the melting temperature of the crystalline phase, the mechanical properties of SIPCs are not sufficient for use as solid state electrolytes, since in this application the polymer electrolyte also acts as a separator. To improve the mechanical properties of SIPCs, where improved, adding small amount of PEG diacrylate $\left(M_{n}=575\right)$ (PEGDA). For this study, the SIPC-2 was chosen due to its high ionic conductance above room temperature. Upon ultraviolet irradiation, free standing films of a single ion conducting poly(ethylene oxide carbonates) were obtained with a small amount of PEGDA networked. However, it is important to note for the following discussion that the SIPC backbone is not involved in the cross-linking polymerization process and only a semi-interpenetrated cross-linked network of PEGDA is formed. This network is likely to act as a molecular mesh-like component, which allows the retention of the mechanical integrity of the blend material at temperatures above the melting temperature of the EO crystalline phase. The conditions were optimized and two formulations were analyzed: 5 wt. $\%$ and 10 wt. $\%$ of PEGDA. The ionic conductivity and thermal analysis of the semi-interpenetrated free standing polymer electrolytes were characterized, and compared with non-cross-linked SIPC-2 (Figure 2).

The ionic conductivity is not significantly impacted when only $5 \mathrm{wt} \%$ of cross-linker is used. The SIPC-2 containing 5 wt. $\%$ of PEGDA shows an ionic conductivity of $3.2 \cdot 10^{-5} \mathrm{~S} \mathrm{~cm}^{-1}$ at $70{ }^{\circ} \mathrm{C}$, whereas without the semi-interpenetrated polymer network, an ionic conductivity of $1.2 \cdot 10^{-4} \mathrm{~S} \mathrm{~cm}^{-1}$ is obtained, Figure 2a. However, when 10 wt.\% of PEGDA is incorporated, a drastic decrease of the ionic conductivity is observed $\left(9.6 \cdot 10^{-7} \mathrm{~S}\right.$ $\left.\mathrm{cm}^{-1}\right)$. Since the decrease in ionic conductivity is also detected at temperatures above the melting temperature of the EO crystalline phase, it is unlikely to be due to difference in the degree of crystallinity, but rather a result of restricted mobility of the SIPC-2 polymer and the semi-interpenetrated PEGDA network. This is indirectly probed by the increase glass transition of the overall system. For instance, when $5 \mathrm{wt} . \%$ PEGDA is added, an increase in the glass transition temperature of the system is observed, going from $-39{ }^{\circ} \mathrm{C}$ to $-28{ }^{\circ} \mathrm{C}$, thereby causing the slight decrease in ionic conductivity.

In addition, the mechanical properties of semi-interpenetrated cross-linked architecture of SIPC-2 with $5 \mathrm{wt} \%$ PEGDA were evaluated by rheometer AR-G2 at $70{ }^{\circ} \mathrm{C}$ and $100{ }^{\circ} \mathrm{C}$. Figure $\mathbf{S 3}$ depicts the viscoelastic properties in the double-logarithmic plots of G' and G" vs. angular frequency. The material's response does not depend on the temperature, and the storage modulus is above the loss modulus in both temperatures, meaning that the polymer electrolyte is in the rubbery plateau region. The good mechanical stability of the semi-interpenetrated crosslinked polymer electrolyte can be concluded. Additionally, the thermogravimetric analysis of SIPC-2 5 wt.\% PEGDA shows thermal stability up to $390^{\circ} \mathrm{C}$, Figure S4.

Single ion conducting polymer electrolytes have attracted a lot of attention in the recent years due to their potential application for energy storage devices. However, to our best knowledge, there are few examples of comparisons between a single ion conducting polymer electrolyte and its analogous conventional SPE. Therefore, in this work, we have compared the single-ion conducting poly(ethylene oxide carbonate) SIPC-2, with the analogous $\mathrm{PEO}_{34}-\mathrm{PC}$ copolymer incorporating the LiTFSI salt (Figure $3 \mathbf{a}, \mathbf{b}$ ). ${ }^{[6]}$ This SPE was prepared by adding $0.58 \mathrm{mmol} \mathrm{Li} / \mathrm{g}$ polymer LiTFSI to previously designed $\mathrm{PEO}_{34^{-}}$ PC. We need to remark that in both systems 5 wt.\% PEGDA was added to improve the mechanical properties and allow for further characterization which required free standing films.

Firstly, the lithium-ion transference numbers of both systems were evaluated using Bruce and Vincent method, Equation S3, Figure 2c. ${ }^{[10]}$ As expected, a high lithium 
transference number of 0.89 is obtained for the SIPC-2, confirming the single-ion conducting nature of this polymer.

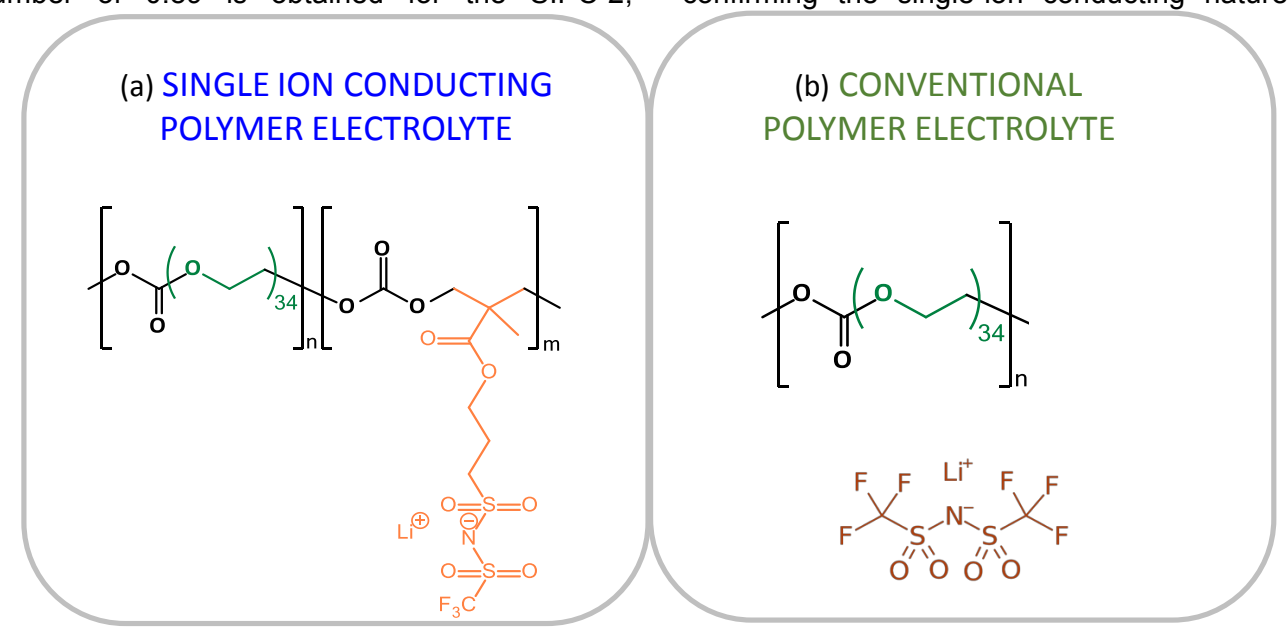

(c)

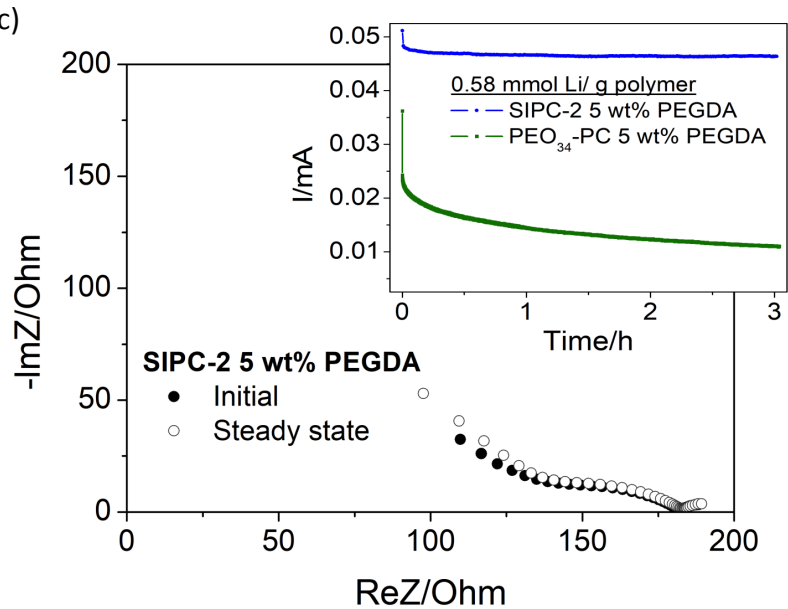

(d)

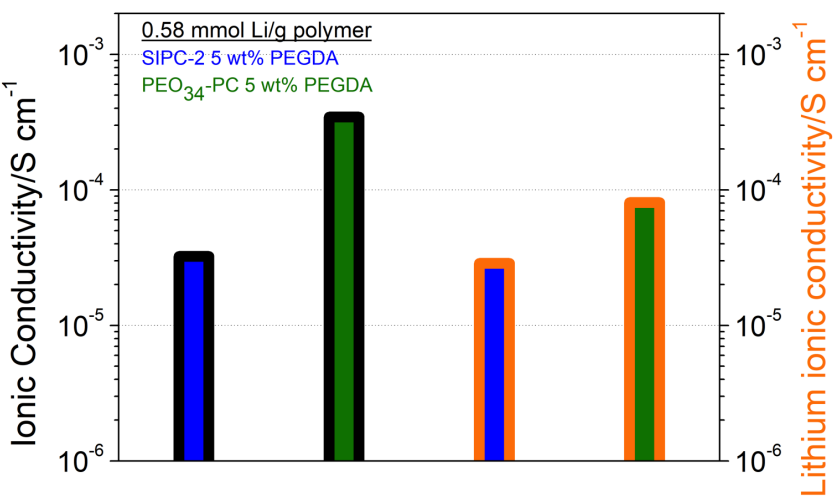

Figure 3. Chemical structure of both semi-interpenetrated cross-linked systems: (a) SIPC-2, and (b) Salt in polymer $\mathrm{PEO}_{34}-\mathrm{PC}$ electrolyte. Comparison of SIPC-2 and $\mathrm{PEO}_{34} \mathrm{PC}$ : (c) Lithium transference number analysis at $70{ }^{\circ} \mathrm{C}$. EIS and $\mathrm{CA}$, and (d) total ionic conductivity and lithium conductivity at $70{ }^{\circ} \mathrm{C}$. Besides, in the corresponding conventional SPE system, a typical low value of 0.23 was measured. Secondly, the ionic conductivity of both systems was analyzed at $70{ }^{\circ} \mathrm{C}$, Figure $3 \mathbf{d}$. As expected the total ionic conductivity at $70{ }^{\circ} \mathrm{C}$ of SIPC-2 is lower than $\mathrm{PEO}_{34}-\mathrm{PC}$ system where both lithium cation and TFSI anion are free to move. Besides, when comparing the lithium conductivity obtained by multiplying the total ionic conductivity by the lithium transference number of each system, in the case of SIPC-2 a value of $2.9 \cdot 10^{-5} \mathrm{~S} \mathrm{~cm}^{-1}$ is detected, while in the case of conventional SPE with dual cation/anion motion it is $7.9 \cdot 10^{-5} \mathrm{~S} \mathrm{~cm}^{-1}$.

Next, ${ }^{7} \mathrm{Li}$ solid state NMR was employed to investigate lithium cation environments and lithium dynamics at different temperatures, Figure 4ab. Pulsed field gradient diffusion measurements were used to measure ${ }^{7} \mathrm{Li}$ and ${ }^{19} \mathrm{~F}$ self-diffusion coefficients at different temperatures, Figure 4a. For the host polymer $\mathrm{PEO}_{34}-\mathrm{PC}$, a clear trend can be observed: TFSI ion diffuses faster than lithium ion, being more pronounced at higher temperatures. Thus, most of the conduction observed by EIS measurements is likely due to the anion mobility (which is in good agreement with the lithium transference number). Conversely, for SIPEs, since the anion is covalently bonded to the polymer backbone, its diffusion is extremely limited. This means that in the case of SIPC-2, the ionic conduction is mainly due to the lithium ion mobility. When comparing the ${ }^{7} \mathrm{Li}$ diffusion of the SIPC-2 with the conventional SPE, the lithium diffusion of SIPC-2 is higher than that of the $\mathrm{PEO}_{34}-\mathrm{PC}$-system, suggesting a higher lithium mobility.

${ }^{7} \mathrm{Li}$ relaxation, $\mathrm{T}_{1}$ experiments are dominated by the molecular reorientation. The ${ }^{7} \mathrm{Li}$ relaxation rates, $\left(\mathrm{R}_{1}=\mathrm{T}_{1}{ }^{-1}\right)$, for both systems are shown in Figure 4b. From the data, a different relaxation behavior can be observed for both systems. The relaxation rate of conventional SPE could be fitted using the Bloembergen, Purcell and Pound (BPP) model for nuclear spin relaxation as in the previously studied $\mathrm{PEO}_{34}-\mathrm{PC}$ system. ${ }^{[6 \mathrm{~b}, \mathrm{c}]} \mathrm{As}$ it was analyzed before, we expect that the quadrupolar interaction will be the dominant mechanism for ${ }^{7} \mathrm{Li}$ longitudinal relaxation for this polymer. ${ }^{[6 b, c]}$ However, in the SIPC-2 system, at high temperature, the relaxation rate is not dependent on the temperature, and therefore, does not follow BPP model. This assumption leads to the suggestion of a distribution of sites. These sites will show different local dynamics, which will cause multiple relaxation mechanisms of the system. 
In order to understand the lithium diffusion data, the conformation of ions is monitored by FTIR-ATR. TFSI anion holds two $\mathrm{SO}_{2}$ groups, which are prone to coordinate with the lithium (a)

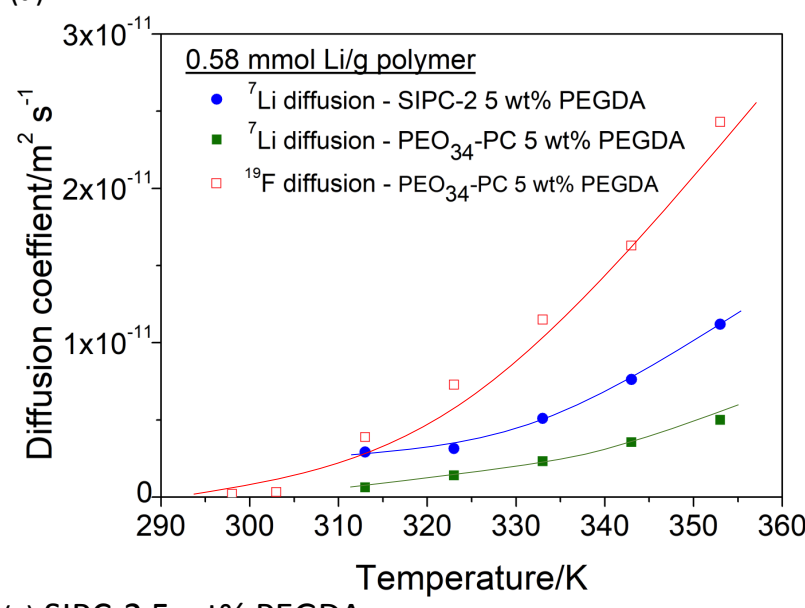

(c) SIPC-2 $5 w t \%$ PEGDA

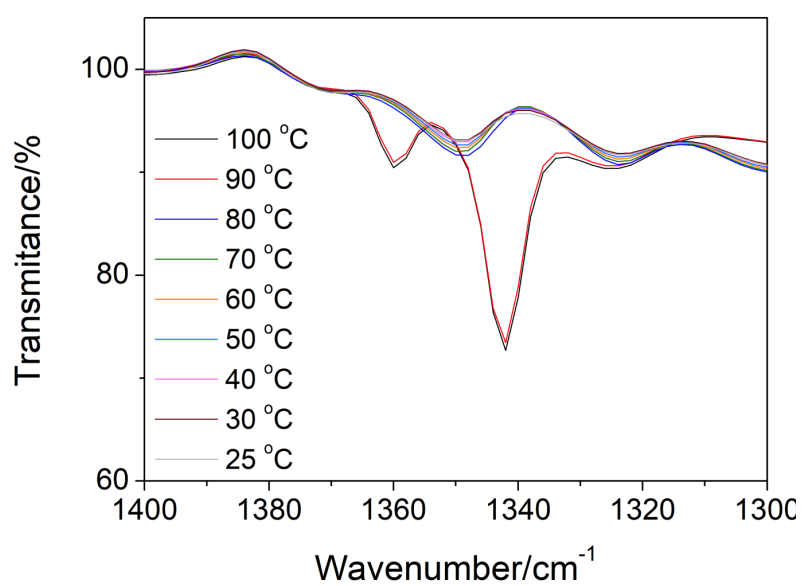

(b)

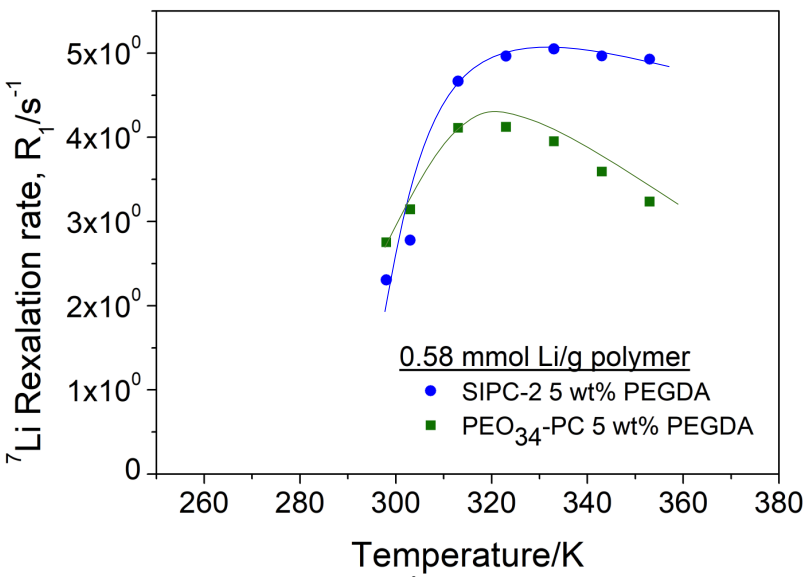

(d) $\underline{\mathrm{PEO}}_{34}-\mathrm{PC} 0.58 \mathrm{mmol}$ Li/g poly. $5 \mathrm{wt} \%$ PEGDA

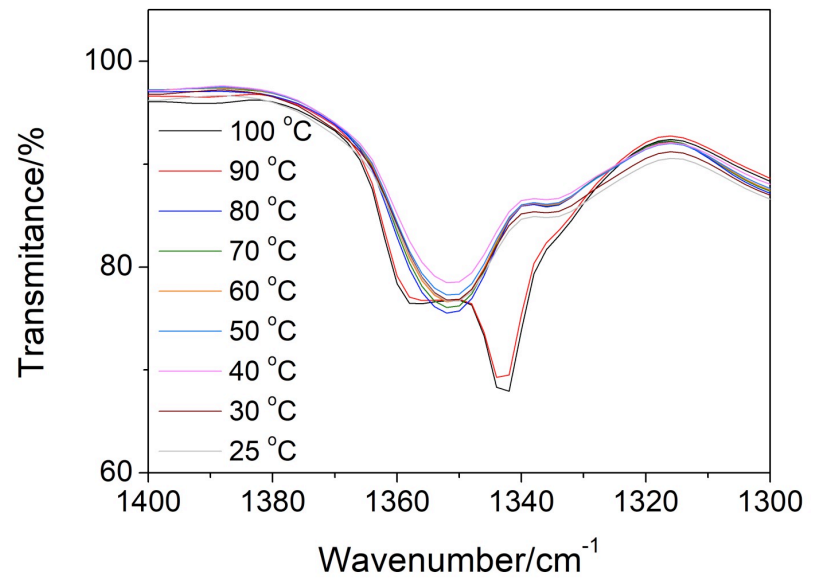

Figure 4. (a) ${ }^{7}$ Li NMR lithium coefficient and (b) ${ }^{7}$ Li relaxation rate, $\mathrm{R}_{1}$, of SIPC-2 5 wt.\% PEGDA and PEO ${ }_{34}$-PC 0.58 mmol LiTFSI/g polymer 5 wt.\% PEGDA at different temperatures. The lines have been drawn in the figures to help to follow the trends. FTIR-ATR comparison of the systems at different temperature (c)

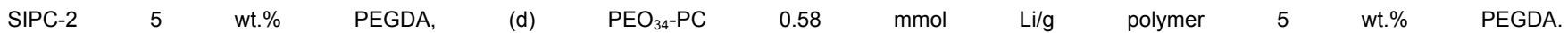
cation, Figure 4cd. In-phase $\left(v_{a}{ }^{i p} \mathrm{SO}_{2}\right)$ and out-of-phase Additionally, as Yoon et al. observed, the cis conformation can $\left(v_{\mathrm{a}}{ }^{\mathrm{op}} \mathrm{SO}_{2}\right)$ antisymmetric and stretching $\mathrm{SO}_{2}$ vibrations are seen pronounced around 1350 and $1330 \mathrm{~cm}^{-1}$ respectively, Figure 4cd. ${ }^{[11]}$ Although it is well known that each vibration is a results of cis and trans conformations, it is reported that the trans conformation is more associated with the $v_{a}{ }^{i p} \mathrm{SO}_{2}$ vibration, and reciprocally for the cis conformation with the $v_{a}{ }^{o p} \mathrm{SO}_{2}$ vibration. ${ }^{[11]}$ Therefore, the conformation distribution can be analyzed qualitatively at different temperatures. In each system a change on the conformation is clearly observed with temperature increase. At temperature bellow $80{ }^{\circ} \mathrm{C}$, each system shows different conformation distributions. In SIPC-2 system, similar contributions of both cis and trans conformation can be observed, Figure 4c, which may be induced by the steric hindrance of the backbone. Besides, in $\mathrm{PEO}_{34}-\mathrm{PC}$ system, although both conformations are detected, trans conformation appears to be the most predominant. However, in both system, at 100 and $90{ }^{\circ} \mathrm{C}$, the cis conformation is mainly pronounced. enhance the lithium transport. ${ }^{[12]}$ Interestingly, in our SIPC-2 system, at temperature below $80{ }^{\circ} \mathrm{C}$, there is a more important contribution of cis conformation than in $\mathrm{PEO}_{34}-\mathrm{PC}$ system. This could explain why higher lithium diffusion coefficients were obtained for SIPC-2 system than for $\mathrm{PEO}_{34}-\mathrm{PC}$ system.

The lithium transport properties of both systems were measured in a lithium symmetric cell at $70{ }^{\circ} \mathrm{C}$, Figure 5. A current of $0.2 \mathrm{~mA} \mathrm{~cm}{ }^{-2}$ was applied to both systems, with a polarization period of 1 hour. Such experiments allow to assess two major criteria of an electrolyte: 1) its lithium transport properties, which needs to be sufficient to sustain the current density applied, and 2) its ability to form a highly conductive solid electrolyte interphase (SEI) under the defined cycling conditions (also influences its electrochemical stability towards lithium metal). A failure of an electrolyte to meet one of these two criteria will lead to poor cycling performance. It is worth mentioning that the SIPC-2 was not able to form a good SEI 
layer by itself and therefore, lithium metal pre-treatment was needed to achieve good cycling performance (refer to experimental section for more details). It is well known that the quality of the SEI formed is highly impacted by the type of lithium counter-anion used, among which the bis (fluorosulfonyl) imide anion (FSI) has been shown to support the formation of stable and high conductive SEl. ${ }^{[13]}$ From Figure 5, a)

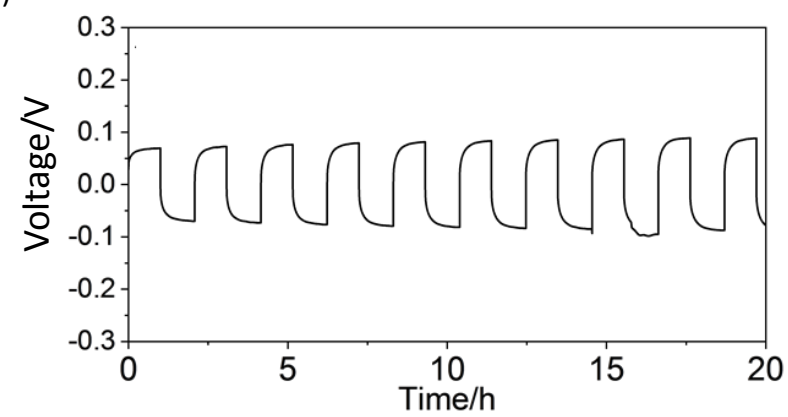

Figure 5. Symmetric cell at $70{ }^{\circ} \mathrm{C}$ under $0.2 \mathrm{~mA} \mathrm{~cm}{ }^{-2}$ polarization: (a) SIPC we can clearly observe that both systems are able to sustain the applied current density. However, the single ion system shows lower overpotential $(80 \mathrm{mV}$ vs. $180 \mathrm{mV}$ ) and a distinct plateau, indicating that this system exhibits better lithium transport properties, while the conventional SPE suffers from lithium transport limitation. The difference in lithium transport performance between the two systems is likely due to the presence of mobile TFSI anion in the conventional system that could promote the formation of a concentration gradient and limits the migration of the lithium ion through the electrolyte.

Prior assessing any cycling performance of the single ion system in a full cell, the electrochemical stability towards oxidation has been assessed, using lithium-metal, SIPC-2 with 5 wt. $\%$ PEGDA and stainless steel cell at $70{ }^{\circ} \mathrm{C}$, Figure S5. The SIPC-2 with 5 wt.\% PEGDA shows the anodic limit at $4.9 \mathrm{~V}$ vs. $\mathrm{Li}^{\prime} \mathrm{Li}^{+}$, which is commonly observed in carbonate containing polymer electrolytes. Such high anodic limit should allow to use high voltage cathode such as lithium cobalt oxide (LCO) or lithium Nickel Manganese Cobalt (NMC). We have evaluated both systems with NMC based cell at $70{ }^{\circ} \mathrm{C}$ (Figure S6). In the first 5 cycles the SIPC polymer electrolyte shows a capacity values of $150 \mathrm{mAh} \mathrm{g}^{-1}$ which is slightly lower the capacity value of the conventional polymer electrolyte $180 \mathrm{mAh} \mathrm{g}^{-1}$. These initial results show the promising performance of SIPC which will be further investigated and optimized in the near future.

\section{Conclusions}

To conclude, an optimized single-ion polymer electrolyte was synthesized combining the most successful chemical units with respect to polymer electrolyte design, ethylene oxide, carbonate and lithium sulfonimide. The single-ion conducting poly(ethylene oxide carbonate) copolymers showed high ionic conductivities and lithium transference number. The SIPC was compared with an analogue conventional polymer electrolyte containing equal molar lithium cation and free TFSI anions. Lithium environments and mobility were compared by lithium PFG NMR, $T_{1}$ measurements and FTIR-ATR analysis. Analyzing lithium transference number, NMR and FTIR-ATR analysis concurred to b)

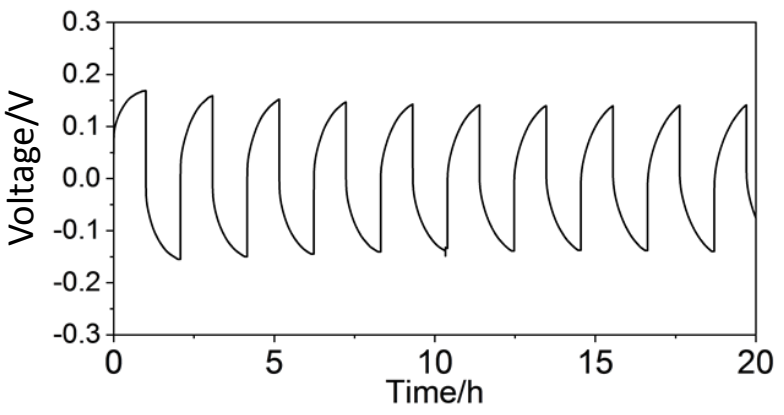

5 wt.\% PEGDA and (b) PEO ${ }_{34}-\mathrm{PC} 0.58 \mathrm{mmol}$ Li/g polymer 5 wt.\% PEGDA. show a favorable lithium diffusion for this SIPE, which could be attributed to $\mathrm{SO}_{2}$ cis conformation. The performances of both polymers electrolytes in lithium symmetric cells was compared, showing superior Lithium ion transfer properties of the single-ion polymer electrolyte. Finally, the initial results of a NMC cell showed the potential use of these type of electrolytes in next generation battery technologies.

\section{Experimental Section}

Dry dimethyl carbonate (99+ \%) (DMC) and 4dimethylaminopyridine (DMAP) (99\%) were purchased from Acros Organics. The later was dried applying vacuum for $4 \mathrm{~h}$ at room temperature prior to use. Poly(ethylene glycol) $\left(M_{n} 1,500 \mathrm{~g} \mathrm{~mol}^{-1}\right)$ was supplied by Fisher Scientific and it was dried by azeotropic distillation in toluene for $8 \mathrm{~h}$. Lithium bis(trifluoromethane)sulfonimide (LiTFSI) (99.9\%) was supplied from Solvionic and the photoinitiator, 2-hydroxy-2methylpropiophenone (DAROCUR) and poly(ethylene glycol) diacrylate (Mn $575 \mathrm{~g} \mathrm{~mol}^{-1}$ ) from Merck. Methanol (MeOH) (reagent grade), dimethylformamide (DMF) (reagent grade) and diethyl ether (Et2O) (Extra Pure, SLR, Stabilized with BHT) were obtained from Scharlab and toluene (HPLC grace), Lithium bromide (reagent plus $\geq 99 \%$ ) and deuterated DMSO (99.8\%) from Merck.

Ester functionalized anionic diol (bis-MPTFSI) was synthesized based on the work described by L. Porcarelli et. al. ${ }^{[8]}$ Before performing the polymerization, the ion exchange of bis-MPTFSI was carried out: potassium cation was changed to lithium cation. 1.1 equimolar amount of $\mathrm{LiClO}_{4}$ was added to the solution of bis-MPTFSI in acetonitrile. After stirring overnight, the $\mathrm{KClO}_{4}$ was removed by filtration, and ACN was removed from the filtrate by rotary evaporation.

The following example is given for the synthesis of SIPC-2 (PEO ${ }_{34}$ :bis-MPTFSI 50:50 mol\%). Monomers, PEG1500 (PEO $\left.{ }_{34}\right)(2 \mathrm{~g}$, $1.33 \mathrm{mmol}, 0.5 \mathrm{eq}$ ) and ester functionalized anionic diol (bis-MPTFSI) $(0.523 \mathrm{~g}, 1.33 \mathrm{mmol}, 0.5$ eq.), together with the catalyst, DMAP, ( 3.25 $\mathrm{mg}, 0.0266 \mathrm{mmol}, 0.01$ ) were introduced into $10 \mathrm{~mL}$ schlenk flask inside argon filled glove box. After, anhydrous dimethyl carbonate (DMC) (1.8 $\mathrm{mL}, 21.8 \mathrm{mmol}$, 8 eq.) was added to the schlenk flask. The schlenk flask was immersed in an oil bath and connected to the vacuum line. First, the reaction was maintained at $130{ }^{\circ} \mathrm{C}$ during $7 \mathrm{~h}$, and finally, the 
temperature was increased to $180{ }^{\circ} \mathrm{C}$ and high vacuum was applied overnight. The purification of the SIPC was carried out by dissolving the polycarbonate in methanol and precipitating in cold diethyl ether. A yield of $85 \%$ was calculated by gravimetric. Three polycarbonate compositions were tailored; 75:25 mol\% (SIPC-1), 50:50 mol\% (SIPC-2) and $25: 75 \mathrm{~mol} \%$ (SIPC-3). The polymer was characterized by ${ }^{1} \mathrm{H}$ NMR (DMSO-d $\mathrm{d}_{6}, 400 \mathrm{MHz}$ ): $\delta=4.55$ (s, OCOOC $\left.\underline{H}_{2} \mathrm{CC} \underline{H}_{2} \mathrm{OOCO}, 4 \mathrm{H}\right), 4.18(\mathrm{t}$, $\left.\mathrm{OCOOC} \underline{\boldsymbol{H}}_{2} \mathrm{CH}_{2}, 4 \mathrm{H}+\mathrm{OCOOCH} \mathrm{CCOOCH}_{2}\right), 3.61\left(\mathrm{t}, \mathrm{OCOOCH}_{2} \underline{\mathrm{CH}}_{2}, 4 \mathrm{H}\right)$, $3.51 \quad$ (s, $\left.\quad \mathrm{OCOCH}_{2} \mathrm{CH}_{2} \mathrm{OCH}_{2} \mathrm{CH}_{2} \mathrm{O}, \quad 128 \mathrm{H}\right), \quad 3.01 \quad(\mathrm{~m}$, OCOOCH $\left.\mathrm{CCOOCH}_{2} \mathrm{CH}_{2} \mathrm{C}_{2}\right), 1.99\left(\mathrm{~m}, \mathrm{OCOOCH}_{2} \mathrm{CCOOCH}_{2} \mathrm{C}_{2}\right), 1.88$ (s, $\mathrm{OCOOCH}_{2} \mathrm{CCH}_{3}, 3 \mathrm{H}$ ).

The SIPCs were dissolved in $\mathrm{MeOH}$ by strong stirring during $10 \mathrm{~min}(0.5$ $\mathrm{g} \mathrm{mL}^{-1}$ ). The solutions were cast on a silicone mould. Then, the solvent was allowed to evaporate at room temperature. The resulting polymers were further dried, under high vacuum at $\mathrm{RT}$, then $60^{\circ} \mathrm{C}$.

The preparation of free standing SIPC was achieved blending the polycarbonates with a cross-linkable polymer, PEG diacrylate $\left(M_{n} 575\right)$ (PEGDA); both polymers $(0.2 \mathrm{~g})$ and photoinitiator (1 wt.\% vs. PEG diacrylate), 2-hydroxy-2-methylpropiophenone, were dissolved in methanol $(0.4 \mathrm{~mL})$, stirred during 10 minutes. First, the solvent was slowly evaporated at room temperature and the evaporation of the solvent was completed applying high vacuum at room temperature overnight. Finally, the membranes were passed 3 times from xenon arc lamp (Helios Italquartz, $45 \mathrm{~mW} \mathrm{~cm}^{-2}$ ).

Free standing conventional polymer electrolytes were prepared as follow: $0.9 \mathrm{~g}$ of polymer and LiTFSI $(0.58 \mathrm{mmol} \mathrm{Li} / \mathrm{g}$ polymer) were dissolved in $0.4 \mathrm{~mL}$ methanol. $0.1 \mathrm{~g}$ PEG diacrylate $\left(M_{n} 575\right)$ and photoinitiator (1 wt.\% vs. PEG diacrylate), 2-hydroxy-2methylpropiophenone were added to the solution. After stirring the solution during 10 minutes, first, the solvent was slowly evaporated at room temperature and the evaporation of the solvent was completed applying high vacuum at room temperature overnight. Finally, the membranes were passed 3 times from xenon arc lamp (Helios Italquartz, $45 \mathrm{~mW} \mathrm{~cm}^{-2}$ ).

Before performing any electrochemical characterization, noncross-linked and cross-linked electrolytes were first dried under vacuum at room temperature during $24 \mathrm{~h}$, and after, the evaporation was completed, increasing the temperature up to $60^{\circ} \mathrm{C}$ and applying vacuum for $24 \mathrm{~h}$.

For symmetric cell analysis, the interpenetrated cross-linked polymer electrolytes were sandwiched between two metallic lithium disks and they were closed in a CR2032 coincells. In the case of the single ion conducting polymer electrolyte, the surface of metallic lithium had to be treated. Therefore, $5 \mu \mathrm{L}$ of $2 \mathrm{M} \mathrm{LiFSI}$ in DME was added in the interphases between lithium and polymer electrolyte. The DME was evaporated before closing the cell at $50^{\circ} \mathrm{C}$ and under vacuum during 30 $\min$.

${ }^{1} \mathrm{H}$, and ${ }^{7} \mathrm{Li}$ Nuclear Magnetic Resonance (NMR) spectra were recorded on Bruker spectrometers at 400 and $500 \mathrm{MHz}$ at room temperature, in $d_{6}-\mathrm{DMSO}$, respectively. Diffusion measurements were carried out on a $300 \mathrm{MHz}$ Bruker Advance III spectrometer with a Diff50 pulsed field gradient probe and a stimulated echo pulse sequence. Relaxation measurements were carried out on the same hardware with a saturation recovery pulse sequence. Attenuated Total Reflectance Fourier Transform Infrared Spectroscopy measurements (ATR-FTIR) were conducted on a Perkin-Elmer Spektrum ATR spectrometer.

The molar masses $\left(M_{n}, M_{w}\right)$ and PDI of SIPCs were measured on a PLGPC 50 gel permeation chromatograph (Agilent Technologies) equipped with an integrated IR detector, a TSK-GEL1SuperAW4000 column (Tosoh) and a SuperAW-L Guardcolumn (Tosoh). A $10 \mathrm{mM} \mathrm{LiBr}$ solution in DMF was used as an eluent with a flow rate of $0.5 \mathrm{~mL} \mathrm{~min}^{-1}$ at $50{ }^{\circ} \mathrm{C}$. Calibration was performed with PEG standards.
Differential Scanning Calorimetry (DSC) was performed on a DSC Q2000 differential calorimeter (TA Instruments). All the experiments were performed under ultrapure nitrogen flow. Samples of $5 \mathrm{mg}$ were used. Measurements were performed by placing the samples in sealed aluminium pans. The samples were first heated at a rate of $20 \mathrm{~K} \mathrm{~min}^{-1}$, from $25{ }^{\circ} \mathrm{C}$ to $100{ }^{\circ} \mathrm{C}$ and they were left $3 \mathrm{~min}$ at $100{ }^{\circ} \mathrm{C}$ to avoid the influence of thermal history, in order to be able to compare the crystallization/melting temperature afterwards. Subsequently, the sample was cooled down to $-70{ }^{\circ} \mathrm{C}$ at a rate of $10 \mathrm{~K} \mathrm{~min}^{-1}$ and subsequently heated to $100{ }^{\circ} \mathrm{C}$ at $10 \mathrm{~K} \mathrm{~min}^{-1}$ after waiting at $-70{ }^{\circ} \mathrm{C}$ during $3 \mathrm{~min}$. Finally, the sample was cooled down to $-70{ }^{\circ} \mathrm{C}$ at a rate of $50 \mathrm{~K} \mathrm{~min}^{-1}$ and subsequently heated to $100{ }^{\circ} \mathrm{C}$ at $50 \mathrm{~K} \mathrm{~min}^{-1}$ after waiting at $-70{ }^{\circ} \mathrm{C}$ during $3 \mathrm{~min}$ ( $T_{g}$ value was determined from this last scan).

The mechanical properties were analysed by rheological measurements using an AR-G2 rheometer (TA Instruments) with parallel geometric plates (diameter $12 \mathrm{~mm}$ ). Angular frequency sweeps were performed in the range of $6^{2}<\omega<6^{-2} \mathrm{rad} \mathrm{s}^{-1}$ at different temperatures $\left(70{ }^{\circ} \mathrm{C}\right.$, and $\left.100{ }^{\circ} \mathrm{C}\right)$ in the linear viscoelastic regime. The time required for a frequency sweep was $5 \mathrm{~min}$. Each measurement was repeated at least two times observing a good reproducibility. On the other hand, the thermogravimetry analysis was performed at $\mathrm{N}_{2}$ atmosphere at $10 \mathrm{~K} \mathrm{~min}^{-}$ 1 in Q500 TA Instruments.

Ionic conductivity, lithium transference number and electrochemical stability window were carried out in a VMP3 (Biologic, Claix, France) potentiostat and all cells were assembled in an argon-filled glove box ( $\mathrm{M}$-Braun $<1 \mathrm{ppm} \mathrm{O}_{2}, \mathrm{H}_{2} \mathrm{O}$ ). Ionic conductivity $(\sigma)$ of the polymer electrolytes was determined by $\mathrm{AC}$ impedance spectroscopy over the frequency range from $100 \mathrm{mHz}$ to $1 \mathrm{MHz}$ with an amplitude of $10 \mathrm{mV}$. The conductivities were analysed in a temperature range down from $100{ }^{\circ} \mathrm{C}$ to $25{ }^{\circ} \mathrm{C}$. The solid polymer electrolytes were closed in CR2032, sandwiched between two stainless steel (SS) electrodes. In all the cases the average surface area of the electrode was $2.01 \mathrm{~cm}^{2}$. Lithium transference number was calculated based on Bruce and Vincent method at $70{ }^{\circ} \mathrm{C} \cdot{ }^{[10]}$ The electrolytes were sandwiched between two lithium disks in CR2032. Symmetric cell tests were performed at $70{ }^{\circ} \mathrm{C}$ after stabilization at that temperature during $24 \mathrm{~h}$. The anodic limit was evaluated between open circuit potential $(\mathrm{OCV})$ and $5.5 \mathrm{~V} \mathrm{vs.} \mathrm{Li}^{+} / \mathrm{Li}$ at a constant rate of $0.5 \mathrm{mV} \mathrm{s}^{-1}$. Full cell analysis was performed at $70{ }^{\circ} \mathrm{C}$. The SPE was sandwiched between a lithium metallic dicks and NMC (111) based cathode. The capacity among the cycles was evaluated at C-rate of $\mathrm{C} / 20$ between $4.2 \mathrm{~V}$ and $2.8 \mathrm{~V}$. In the case of the single ion conducting polymer electrolyte, the same treatment as for the lithium symmetric cell was performed in the lithium electrode. Before assessing any analysis, the cells were left to stabilize at $70^{\circ} \mathrm{C}$ during $24 \mathrm{~h}$.

\section{Acknowledgements}

We are grateful to the financial support of the European Research Council by the Starting Grant Innovative Polymers for Energy Storage (iPes) 306250 and IONBIKE (H2020-MSCARISE-2018-823989), and by the Basque Government through ETORTEK Energigune 2013 and IT 999-16. Leire Meabe thanks Spanish Ministry of Education, Culture and Sport for the predoctoral FPU fellowship received to carry out this work. The authors thank for the technical and human support provided by SGIker of UPV/EHU for the NMR facilities of Gipuzkoa campus. The authors thank also Dr. Jose Ignacio Miranda (SGlker) for useful and essential support. Authors would like to thank the human support of Dr. Haijin Zhu and Dr. Luke O'Dell. 
Keywords: Single ion conducting polycarbonate ethylene oxide - polymer electrolyte $\cdot$ polycondensation $\cdot$ lithium battery

[1] J. Mindemark, M. J. Lacey, T. Bowden and D. Brandell, Progress in Polymer Science 2018, 81, 114-143.

[2] a) H. Zhang, C. Li, M. Piszcz, E. Coya, T. Rojo, L. M. RodriguezMartinez, M. Armand and Z. Zhou, Chemical Society Reviews 2017, 46 797-815; b) G. Jo, H. Jeon and M. J. Park, ACS Macro Letters 2015, 4, 225-230; c) S. Li, A. I. Mohamed, V. Pande, H. Wang, J. Cuthbert, X. Pan, H. He, Z. Wang, V. Viswanathan, J. F. Whitacre and K. Matyjaszewski, ACS Energy Letters 2018, 3, 20-27.

[3] a) R. Meziane, J.-P. Bonnet, M. Courty, K. Djellab and M. Armand, Electrochimica Acta 2011, 57, 14-19; b) J. L. Thelen, S. Inceoglu, N. R. Venkatesan, N. G. Mackay and N. P. Balsara, Macromolecules 2016 49, 9139-9147; c) C. Jangu, A. M. Savage, Z. Zhang, A. R. Schultz, L. A. Madsen, F. L. Beyer and T. E. Long, Macromolecules 2015, 48, 4520-4528; d) R. Bouchet, S. Maria, R. Meziane, A. Aboulaich, L. Lienafa, J.-P. Bonnet, T. N. T. Phan, D. Bertin, D. Gigmes, D. Devaux, R. Denoyel and M. Armand, Nature Materials 2013, 12, 452.

[4] a) H. T. Ho, A. Tintaru, M. Rollet, D. Gigmes and T. N. T. Phan, Polymer Chemistry 2017, 8, 5660-5665; b) L. Porcarelli, P. S. Vlasov, D. O. Ponkratov, E. I. Lozinskaya, D. Y. Antonov, J. R. Nair, C. Gerbaldi, D. Mecerreyes and A. S. Shaplov, European Polymer Journal 2018, 107, 218-228; c) L. Porcarelli, A. S. Shaplov, F. Bella, J. R. Nair, D. Mecerreyes and C. Gerbaldi, ACS Energy Letters 2016, 1, 678-682; d) G. Luo, B. Yuan, T. Guan, F. Cheng, W. Zhang and J. Chen, ACS Applied Energy Materials 2019, 2, 3028-3034

[5] a) S. Feng, D. Shi, F. Liu, L. Zheng, J. Nie, W. Feng, X. Huang, M. Armand and Z. Zhou, Electrochimica Acta 2013, 93, 254-263; b) S. Inceoglu, A. A. Rojas, D. Devaux, X. C. Chen, G. M. Stone and N. P.
Balsara, ACS Macro Letters 2014, 3, 510-514; c) C. Sångeland, R. Mogensen, D. Brandell and J. Mindemark, ACS Applied Polymer Materials 2019, 1, 825-832.

[6] a) W. He, Z. Cui, X. Liu, Y. Cui, J. Chai, X. Zhou, Z. Liu and G. Cui, Electrochimica Acta 2017, 225, 151-159; b) L. Meabe, T. V. Huynh, N. Lago, H. Sardon, C. Li, L. A. O'Dell, M. Armand, M. Forsyth and D. Mecerreyes, Electrochimica Acta 2018, 264, 367-375; c) L. Meabe, T. V. Huynh, D. Mantione, L. Porcarelli, C. Li, L. A. O'Dell, H. Sardon, M. Armand, M. Forsyth and D. Mecerreyes, Electrochimica Acta 2019, 302, 414-421; d) M. Nakamura and Y. Tominaga, Electrochimica Acta 2011, 57, 36-39; e) Y. Tominaga, K. Nakano and T. Morioka, Electrochimica Acta 2019, 312, 342-348; f) Y. Tominaga, T. Shimomura and M. Nakamura, Polymer 2010, 51, 4295-4298.

[7] D. Devaux, R. Bouchet, D. Glé and R. Denoyel, Solid State lonics 2012, 227, 119-127.

[8] L. Porcarelli, K. Manojkumar, H. Sardon, O. Llorente, A. S. Shaplov, K. Vijayakrishna, C. Gerbaldi and D. Mecerreyes, Electrochimica Acta 2017, 241, 526-534.

[9] K. Deng, S. Wang, S. Ren, D. Han, M. Xiao and Y. Meng, ACS Applied Materials \& Interfaces 2016, 8, 33642-33648.

[10] J. Evans, C. A. Vincent and P. G. Bruce, Polymer 1987, 28, 2324-2328.

[11] J.-C. Lassègues, J. Grondin, C. Aupetit and P. Johansson, The Journal of Physical Chemistry A 2009, 113, 305-314.

[12] H. Yoon, A. S. Best, M. Forsyth, D. R. MacFarlane and P. C. Howlett, Physical Chemistry Chemical Physics 2015, 17, 4656-4663.

[13] a) J. Qian, W. A. Henderson, W. Xu, P. Bhattacharya, M. Engelhard, O Borodin and J.-G. Zhang, Nature communications 2015, 6, 6362; b) M. Wang, L. Huai, G. Hu, S. Yang, F. Ren, S. Wang, Z. Zhang, Z. Chen, Z. Peng, C. Shen and D. Wang, The Journal of Physical Chemistry C 2018, 122, 9825-9834. 